\title{
Seroprevalence of Hepatitis B\&C and its Association with Stroke in Local Population
}

\author{
Amsal Amjad, Benash Altaf, Farah Amir Ali, Mirza Aroosa Beg
}

\begin{abstract}
Background:Pandemics of viral origin are spreading at alarming rate worldwide. Acquired immune deficiency syndrome (AIDS) caused by human immunodeficiency virus (HIV), hepatitis B and Hepatitis C (HCV) are lethal threats to the human health. HCV remains a serious issue due to long-term consequences of the infection. HCV infection has a role in the development and progression of carotid atherosclerosis and stroke due to altered lipid metabolism. Association of hepatitis with stroke is still hypothesized due to conflicting results documented by various researchers. Aim of this study is to explore association of $\mathrm{HBV}$ and $\mathrm{HCV}$ with stroke as the prevalence of this issue in Faisalabad is $21 \%$ which is higher than other regions of Punjab Pakistan.

Methods: This is a hospital-based retrospective study from July 2018 to September 2018 at a private hospital of Faisalabad. It comprised of 226 subjects. After taking ethical approval from the ethic research committee, data was retrieved from centrally database medical records. Data was transported to SPSS 21 for analysis. Frequency and percentages were obtained for categorical variables. Association between hepatitis and stroke was tested by Chi square and logistic regression to obtained odd ratio. P value $\leq 0.05$ was considered as significant.

Results: Mean age of the studied population was $51.2 \pm 27.03 .38 .5 \%$ and $4 \%$ of the studied population had hepatitis $\mathrm{C}$ and $\mathrm{B}$ respectively. $\mathrm{HCV}$ was significantly associated with stroke $(\mathrm{P}=.005 *)$

Conclusion: $\mathrm{HCV}$ is more prevalent viral infection in local population and is the independent risk factor for stroke Key Words: HBV,HCV, Stroke, Association, lipid metabolism.
\end{abstract}

\section{Introduction}

Burden of lethal viral infections are continuously increasing at an alarming rate all over the world. World health organization (WHO) executive board estimated that 1 Million mortalities each year are attributed to viral hepatitis which is $2.7 \%$ of the total deaths occurring in the world. ${ }^{1} 11.5 \%$ cases of active hepatitis $\mathrm{C}$ (HCV) was reported among the general adult Pakistani population which is expected to increase in coming decades mainly due to widespread use of unsafe medical procedures. ${ }^{2,3}$ Hepatitis is caused by one of the five known viruses (A,B,C,D,E) which primarily infects the liver. Hepatitis $\mathrm{A}$ and $\mathrm{E}$ are common in regions where water and sanitation problems exist like Pakistan and Bangladesh. ${ }^{4}$ However, HBV and HCV infections are most commonly found in subjects receiving blood transfusions and organ.

Dr. Amsal Amjad

Demonstrator

Aziz Fatimah Medical and Dental College, Faisalabad

Dr. Benash Altaf

Assistant Professor

Aziz Fatimah Medical and Dental College,

Faisalabad.

Dr. Farah Amir Ali

Professor

Aziz Fatimah Medical and Dental College,

Faisalabad.

Dr. Mirza Aroosa Beg

Assistant Professor

Sindh Institute of Urology and Transplantation Karachi

Correspondence:

Dr. Benash Altaf

Email.altafbenash@gmail.com transplantations. It is also prevalent among the health care providers who sustain accidental needle pricks while caring these patients. According to the latest figure, about 170 million people are the victim of this lethal virus and are the leading cause of liver transplantation. $0.85-5.5 \%$ of the cases with $\mathrm{HCV}$ infection are reported by previous studies. ${ }^{5} \mathrm{HCV}$ is belongs to a family known as Flaviviridae with an approximately $9.6 \mathrm{~kb}$ singlestranded, positive sense RNA genome. ${ }^{6}$ It can be diagnosed by either checking for viral load through the PCR or by looking for the antibodies been produced against the virus itself. Unfortunately, no vaccine is available for this rapidly spreading virus. Important issue regarding this virus is that it can easily spread from person to person through infected blood and instruments. Perhaps, this is one of the reasons why this bug is based worldwide. It is important to highlight un-documented cases especially in third world countries where still many of the cases are left unnoticed. ${ }^{7}$ About $80 \%$ of the infected subjects develop chronic infection leading to liver cirrhosis. Hepatitis ' $\mathrm{C}$ ' virus also has extra hepatic manifestations like type II diabetes, autoimmune thyroiditis, cardiovascular and cerebrovascular diseases most commonly ischemic stroke. Steatosis, and oxidative stress due to inflammation provoking the carotid atherosclerosis and plaques in most of the cerebral vessels are the contributing factors for the ischemic stroke. ${ }^{8,9}$ Steatosis leading to plaque formation 
is most probably due to the fact that virus itself require fat for its replication and virion production by altered metabolism, leading to decrease reabsorption of fat and subsequent hyperlipdimia. ${ }^{8}$ This altered lipid metabolism by $\mathrm{HCV}$ virus is the most probable explanation of pathophysiology for stroke in $\mathrm{HCV}$ infected patients. ${ }^{10}$ Strong supportive evidences are available showing the association of $\mathrm{HCV}$ with stroke but some studies did not find this association. Documentation concerning link of $\mathrm{HCV}$ and stroke are still controversial so there is need to explore this relationship. ${ }^{12}$ Current study is aimed to focus on the association of $\mathrm{HCV}$ and $\mathrm{HBV}$ with ischemic stroke. In support of this, recent researches are available showing cerebrovascular and cardiovascular diseases are commonest ailments affecting our community and subsequently leading to morbidity and mortality. Hence, this emerging issue is contributing a great burden on our society. ${ }^{13}$ However, it is preventable and $95 \%$ of chronic infection can be cured by using the standard protocol and right treatment guidelines. ${ }^{14}$

\section{Material \& Methods}

This is a hospital-based retrospective study of three months from July 2018 to September 2018 at a private tertiary care hospital in Faisalabad. After taking ethical approval from the ethic research committee of the concerned hospital and permission from head of respective ward, data was requested to retrieve from centrally database medical records with the cooperation of IT department of the hospital. However, informed consent of the patient was not needed as including patient's data was anonymized and decoded. ${ }^{11}$ Our inclusion criteria was patients admitted in medical ward in this duration with either stroke or diagnosed HBV and HCV. Subjects with other diseases were excluded. Total of 226 patients were admitted with HBV, HCV and stroke in this duration, which was the targeted population of present study. Data of the subjects of interest concerning age, gender and diagnosis was sorted out on excel and transferred to SPSS 21. It was analyzed for frequency and distribution of Hepatitis and stroke, Chi square test $\left(\mathrm{X}^{2}\right)$ was performed to assess the association of $\mathrm{HCV}$ and HBV with stroke with 95\% confidence interval. To estimate the relative risk, odd ratios were determined by logistic regression analysis. $\mathrm{P}$ value $\leq 0.05$ was considered to be significant.

Results

Current study comprised of 226 subjects from a private tertiary care hospital of Faisalabad. Mean age was found to be $51.2 \pm 27.03$. Out of 226 subjects $50.4 \%$ were males and $49.6 \%$ were females, showing that male presentation in medical ward was more than females. Figure 1 is showing the frequencies of $\mathrm{HBV}, \mathrm{HCV}$ and stroke. $38.5 \%$ and $4 \%$ of the studied population was hepatitis $C$ and $B$ seropositive respectively. Results reveal that hepatitis C was more prevalent as compared to hepatitis B. Taking into account for stroke, $76.5 \%$ of patients were reported. Figure 2 is indicating that the $79.3 \%$ of hepatitis C patients were also affected by stroke. $\mathrm{X}^{2}$ test shows significant association of hepatitis $\mathrm{C}$ with stroke. Odd ratio of 1.29 ( $\mathrm{p}$ value $0.005^{*}, 95 \% \mathrm{CI}$ ) for anti-HCV seropositive patient is showing that these patients have 1.29 times more risk for developing stroke in contrast to seronegative subjects. Figure 3 is showing that the stroke is also found in $66 \%$ of the seropositive HBsAg patients; however, this association was not statistically significant, most probably due to smaller number of hepatitis B patients in our study ( $\mathrm{p}$ value 0.480 ). This study also revealed that the hepatitis $\mathrm{C}$ and $\mathrm{B}$ as well as stroke are more prevalent among females in contrast to males. Difference concerning stroke was statistically significant but was not statistically significant in respect to hepatitis among the gender. (Table 1) .

Table 1: Distribution of Hepatitis and Stroke among Gender ( $=226)$

\begin{tabular}{|c|c|c|c|c|c|}
\hline \multirow[b]{2}{*}{ Gender } & \multicolumn{2}{|c|}{ Hepatitis C (anti HCV) } & \multicolumn{2}{|c|}{ Hepatitis B ( HBsAg) } & \multirow{2}{*}{$\begin{array}{c}\text { Stroke } \\
\text { Frequency } \\
\mathrm{N}(\%)\end{array}$} \\
\hline & $\begin{array}{c}\text { Seropositive } \\
\text { Frequency } \\
\mathrm{N}(\%)\end{array}$ & $\begin{array}{c}\text { Seronegative } \\
\text { Frequency } \\
\mathrm{N}(\%)\end{array}$ & $\begin{array}{c}\text { Seropositive } \\
\text { Frequency } \\
\mathrm{N}(\%)\end{array}$ & $\begin{array}{l}\text { Seronegative } \\
\text { Frequency } \\
\mathrm{N}(\%)\end{array}$ & \\
\hline $\begin{array}{l}\text { Male } \\
\text { (114) }\end{array}$ & $42(36.8)$ & $72(63.2)$ & $3(2.6)$ & 111(97.4) & $79(69.3)$ \\
\hline $\begin{array}{c}\text { Female } \\
\text { (112) }\end{array}$ & $45(40.2)$ & $67(59.8)$ & $6(5.4)$ & 106(94.6) & $94(83.9$ \\
\hline P values & \multicolumn{2}{|c|}{$\frac{1}{0.33}$} & \multicolumn{2}{|c|}{0.68} & $0.012^{*}$ \\
\hline
\end{tabular}

Proportions are compared by chi-square test. $\mathrm{P}$ value $\leq 0.05$ was considered to be significant.

Figure1:Frequencies and Percentages of Hepatitis and Stroke among the hospitalized patients $(\mathrm{N}=226)$

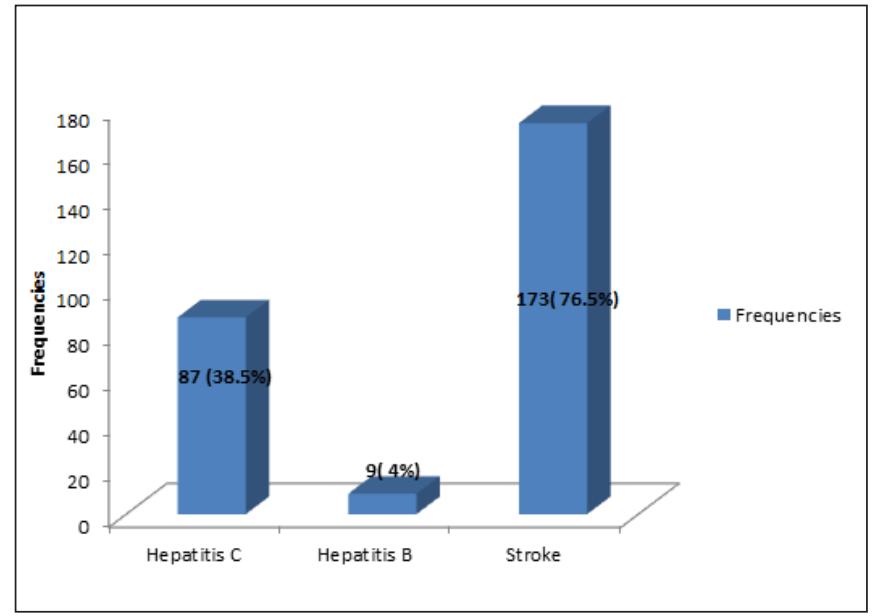


Figure 2: Frequency and Percentages of HCV Patients with and without Stroke. $(\mathrm{N}=87)$

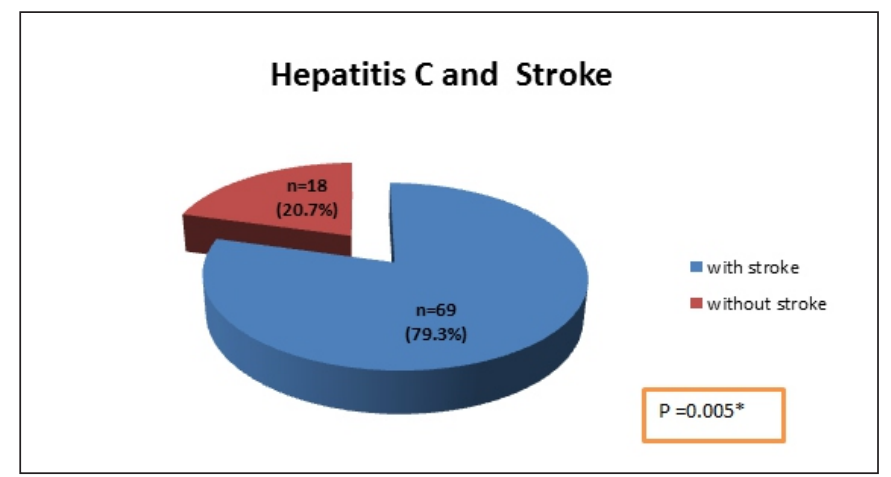

Figure 3: Frequency and Percentages of HBV Patients with and without Stroke. $(\mathrm{N}=09)$

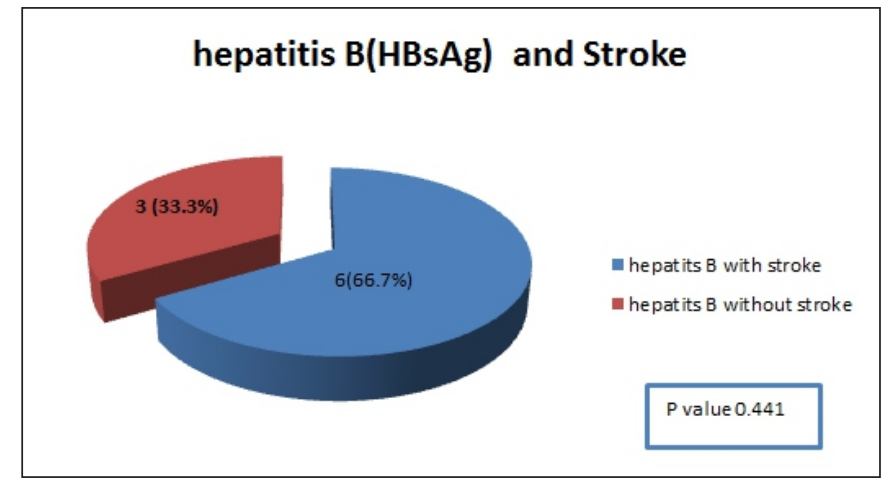

Discussion

Present retrospective study was conducted to determine the frequency of HCV and HBV in the local population and to high light their association with stroke. Hepatitis is spreading at a break neck pace worldwide. It is continuously increasing in Pakistan involving all the provinces due to increase usage of unsterile syringes, needles, blades, instruments and unchecked blood transfusions while visiting hospitals and barbers ${ }^{15}$. Researches in past also reported high incidence of this issue in Punjab. ${ }^{16}$ Very few epidemiological studies are available documenting slightly higher prevalence of $\mathrm{HCV}$ in Faisalabad than other regions of Punjab. ${ }^{17}$ Data concerning its incidence and risk factors in Faisalabad which is third largest city of Pakistan with population of 5.28 million are still obscure. ${ }^{18}$ Lack of awareness and knowledge are highly contributed to its spread and its complications. Proper steps must be taken at government level for the awareness of people to make them enough aware of its complications and to make them know that how they can be safe from contracting this infection by seeking proper precautions. Patients affected with HCV are not only compromising the quality of their lives but also losing courage to live, subsequently putting the burden of the disease on their families and communities.Moreover, affected people are from lower socioeconomic status who even don't bear expenditures of hospital and are also non-compliant to medications. Different studies reported $\mathrm{HCV}$ affected patients have complications that affect their quality of life. One of the complications is known to get ischemic stroke. ${ }^{10,12}$ However, results regarding this statement are still inconsistent, so taking this into account Liao CC, and his colleagues studied the population at Taiwan and found that $\mathrm{HCV}$ patients are at risk for developing stroke. ${ }^{7}$ Past researches documented varying etiologies of stroke in $\mathrm{HCV}$ subject. Some researchers reported altered cerebral function in the $\mathrm{HCV}$ infection which is responsible for cognitive disturbance as well as psycho-neurological issue. ${ }^{19}$ Present study focused to determine the frequencies of various viral infections and stroke. It revealed that during three months $38.5 \%$ and $4 \%$ of the targeted population was seropositive for anti $\mathrm{HCV}$ and HBsAg respectively. It is clear from the results that HCV is more prevalent in Faisalabad, Punjab than other viral infections. This documentation of our study is in agreement with Maan MA who in his two year retrospective study at district headquarter (DHQ) hospital, Faisalabad, estimated $21.99 \%$ of prevalence in Faisalabad, Punjab, which is slightly higher than other regions of Pakistan. ${ }^{17}$ Highest proportions of $\mathrm{HCV}$ serological markers, was found in injection drug users. Preventive strategies on intervention and facilitation of access to healthcare program to safe the local population are required. ${ }^{17}$ This study also found the higher seropositivity for anti $\mathrm{HCV}$ and HBsAg in females in contrast to males, this finding is in consistent with Ramarokoto $\mathrm{CE}$ et al study who reported higher frequency of $\mathrm{HCV}$ in females than males $(71.42 \% \mathrm{Vs}$ $28.57 \%$ ) in his studied population. ${ }^{5}$ Result of current study was found that the $79.3 \%$ of the HCV patients develop stroke and odd ratio of 1.29 (p value $0.005^{*}$ ) is indicating that these patient poses 1.29 times more risk for stroke than patients with other causes. This finding is suggesting that HCV infection is the independent risk factor for stroke. Current findings are strongly supported by community-based prospective cohort study by Lee $\mathrm{MH}$ and his co researches who also labeled the chronic $\mathrm{HCV}$ infection as an independent risk predictor of stroke and cerebrovascular deaths with increasing serum HCV RNA level. ${ }^{20}$ Our aim of the study was also to analyze the data for association of $\mathrm{HBV}$ with stroke and found $66 \%$ of the subjects were with stroke but this association was not significant probably due to less number of hepatitis B patients ( $p$ value 0.48 ) in our collected data. More prospective cohort studies will be needed to 
confirm this association with underlying biological mechanisms in the future.

\section{Limitation of the study}

As this is a retrospective study, so it may also include some subclinical HCV infections associated with stroke, which were left un-diagnosed. Duration of three months is not sufficient, large duration studies on a broader scale are required for monitoring these trends, and further observation regarding spread of this lethal disease.

\section{Conclusion}

$\mathrm{HCV}$ is more prevalent viral infection in local population and is the independent risk factor for stroke. There is urgent need for policies and preventive strategies at government level. Proper planning is required to eradicate this infection concerning the safety measures, and proper disposal of waste and infective materials in hospitals, as the, most common routes for its spread are the syringes, surgical procedures and blood transfusion.

Funding Source: Nil

Conflicts of interest: Nil

\section{References}

1.WHO Executive Board.Viral hepatitis. Report by the secretariat, 2009. EB126/15.12.2009. Nov [Last accessed on 3 May 2012]. Available from: http://www.apps.who.int/gb/ebwha/pdf files/EB 126/B 126_15-en pdf.

2. Umer M, Iqbal M. Hepatitis C virus prevalence and genotype distribution in Pakistan: Comprehensive review of recent data. World Gastroenterol 2016; 22(4):1684- 1700 .

3. Arshad A, Ashfaq UA. Epidemiology of hepatitis C infection in Pakistan: current estimate and major risk factors. Critical Reviews ${ }^{\mathrm{TM}}$ in Eukaryotic Gene Expression 2017;27(1):63-77. doi: 10.1615/CritRevEukaryotGeneExpr.2017018953. Review.

4. Antony J, Celine T. A Hospital-based Retrospective Study on Frequency and Distribution of Viral Hepatitis.Jglob Infect Dis .2014; 6(3):99-104

5. Ramarokoto CE, Rakotomanana F, Ratsitorahina M, etal. Seroprevalence of hepatitis $\mathrm{C}$ and associated risk factors in urban areas of Antananarivo, Madagascar. BMC Infect Dis. 2008 ; 8:25. doi: 10.1186/1471-2334-825.
6. NazA, Mukry SN, Naseer I, Shamsi TS. Evaluation of efficacy of serological methods for detection of $\mathrm{HCV}$ infection in blood donors. A single centre experience. Pak J Med Sci.2018: 34(5):1204-1208.

7. Liao CC, Su TC, Sung FC, Chou WH, Chen TL. Does hepatitis $\mathrm{C}$ virus infection increase risk for stroke? A population-based cohort study. PloS one. 2012 ;7(2):e31527. doi: 10.1371/journal.pone.0031527.

8. Negro F. Facts and fictions of HCV and comorbidities: steatosis, diabetes mellitus, and cardiovascular diseases. Journal of hepatol. 2014;61(1):S69-78.

9. Flamm SL.Chronic hepatitis C infection. JAMA.2003;289(18):2513-7.Review.

10. Forton DM, Allsop JM, Main J, Foster GR, Thomas HC, Taylor-Robinson SD. Evidence for a cerebral effect of the hepatitis C virus. Lancet. 2001;358(9275):38-9.

11. Borovecki A, Mlinaric A, Horvat M, Supak Smolcic V. Informed consent and ethics committee approval in laboratory medicine. Biochem Med (Zagreb) 2018 ;28(3):030201 Review.

12. He Huang, Kang R, Zhao Z. Hepatitis C virus infection and risk of stroke: a systematic review and meta-analysis. PLoS One. 2013; 8(11):e81305.Review

13. Feigin VL. Stroke in developing countries: can the epidemic be stopped and outcomes improved?.The Lancet Neurology. $2007 ; 6(2): 94-7$.

14. Standard Treatment Guidelines, 6th edi, 2010 Ministry of Health (GNDP) Ghana, ISBN 978-9988-12538-7.

15. Mahmood H, Raja R. Risk Factors of Hepatitis $C$ in Pakistan. Gastroenterol Hepatol Open Access 2017; 7(6): 00259. Review.

16.Al Kanaani Z, Mahmud S, Kouyoumjian SP, AbuRaddad LJ. The epidemiology of hepatitis $C$ virus in Pakistan: systematic review and meta-analyses. R Soc Open Sci. 2018 Apr 11;5(4):180257. 
17. Maan MA, Fatma H, Muhammad J. Epidemiology of hepatitis $\mathrm{C}$ viral infection in Faisalabad, Pakistan: a retrospective study (2010-2012). African health sciences. 2014;14(4):810-4.

18. World Population Review: Report,Punjab Population 2018:http://worldpopulationreview.com/territories/punj ab-population.
19. Sheikh MY, Choi J, Qadri I, Friedman JE, Sanyal AJ. Hepatitis C virus infection: molecular pathways to metabolic syndrome. Hepatology. 2008 ; 47(6):2127-33.

20. Lee MH, Yang HI, Wang CH, Jen CL, Yeh SH, Liu CJ, You SL, Chen WJ, Chen CJ. Hepatitis C virus infection and increased risk of cerebrovascular disease. Stroke. 2010;41(12):2894-900.

\section{Author`s Contribution}

Dr. Amsal Amjad: Study design, data collection, Interpretation of results, manuscript writing

Dr. Benash Altaf: Statistical analysis, interpretation of results, formulation of tables, writing the manuscript. Reviewed and approved the manuscript.

Dr. Farah Amir Ali: Acquisition of data, interpretation of results, editing and formatting the manuscript. Reviewed and approved the manuscript.

Dr. Mirza Aroosa Beg: Statistical analysis, interpretation of results, formulation of tables, writing the manuscript. Reviewed and approved the manuscript. 